\title{
Editorial: Urban Greening in the Global South: Green Gentrification and Beyond
}

\author{
Pedro Henrique Campello Torres ${ }^{1,2,3 *}$, Clara Irazábal ${ }^{4}$ and Pedro Roberto Jacobi ${ }^{1,5}$ \\ ${ }^{1}$ Institute of Energy and Environment, University of São Paulo, São Paulo, Brazil, ${ }^{2}$ School of Arts, Sciences and Humanities \\ (EACH), University of São Paulo, São Paulo, Brazil, ${ }^{3}$ Institute of Urban and Regional Research and Planning (IPPUR/UFRJ), \\ Rio de Janeiro, Brazil, ${ }^{4}$ School of Architecture, Planning, and Preservation, University of Maryland, College Park, MD, \\ United States, ${ }^{5}$ Institute of Advanced Studies, University of São Paulo, São Paulo, Brazil
}

Keywords: green gentrification, urban greening, green inequalities, cities, Global South

\section{Editorial on the Research Topic}

Urban Greening in the Global South: Green Gentrification and Beyond

\section{INTRODUCTION}

The BiodiverCities initiative, which is a roadmap for sustainable city development that shifts traditional gray infrastructure to more natural-based solutions, was presented at the World Economic Forum, 2022. Another report that was released on the same day by the nongovernmental organization Oxfam pointed out that during the COVID-19 pandemic, 99\% of people's income fell, among other negative developments (OXFAM, 2022). As a result, more than 160 million were pushed into poverty, while a new person became a billionaire every $26 \mathrm{~h}$. The

\section{OPEN ACCESS}

Edited and reviewed by: Stephan Pauleit,

Technical University of

Munich, Germany

${ }^{*}$ Correspondence: Pedro Henrique Campello Torres phcampellotorres@gmail.com

Specialty section: This article was submitted to Urban Greening,

a section of the journal Frontiers in Sustainable Cities

Received: 30 January 2022 Accepted: 10 February 2022 Published: 08 March 2022

Citation:

Torres PHC, Irazábal $C$ and Jacobi PR (2022) Editorial: Urban Greening in the

Global South: Green Gentrification and Beyond. Front. Sustain. Cities 4:865940. doi: 10.3389/frsc.2022.865940 wealth of the richest, all of whom are white men, grew by $\$ 5$ trillion in the same period.

This Research Topic is about environmental inequality. While solutions and innovations to mitigate environmental damage are discussed, another fraction exposes the face of perverse and unequal impacts, which disproportionately affect the most vulnerable populations. The objective of the Research Topic was to contribute to fill the gap in environmental inequalities studies by presenting empirical research that focuses on the Global South. In our view, this gap perpetuates a limited understanding of the relationship between urban greening, unequal and uneven development, and growth, which includes the provision of ecosystem services and social equity.

With this, the organizers sought to expand both the repository of Global South case studies and South-South or North-South comparisons. Therefore, the main goal of this Research Topic is to develop scientific dialogue on approaches to greening cities in the Global South that exacerbate green inequalities and gentrification, as well as those that create greener and healthier cities for all. Within this Special Issue, we intended to receive papers on (1) concrete cases of green inequalities and (2) good practices and interventions.

After being reviewed by experts, a notable aspect was the sheer variety of articles that were published: original research, policy briefs, systematic reviews, mini-reviews, and policy and practice reviews. Eleven articles were approved from a total of 30 authors, most of whom came from Brazilian institutions. This can be explained by the fact that two special issue editors are based in Brazil, while the others authors are from Germany, the Netherlands, and the United States. Articles represent different kinds of expertise and areas of knowledge, including environmental sciences, architecture and urbanism, history, biology, urban planning, sociology, and political science, among others. 
We would have liked to have more contributions from the Global South, although territories in Brazil, Chile, Indonesia, and Barbuda were included. Two possible factors contributed to this: language constraints and the costs associated with open access publications.

Forty-six keywords are mentioned in the 11 articles, highlighting each text's particularity. Of these, only five mention "global south" (four times), "environmental justice" (three times), "green gentrification" (three times), "green infrastructure" (three times), and "gentrification" (two times). As such, the current set of articles published here should be seen as the starting point of an intellectual exploration that exposes global contradictions and environmental inequalities. Based on the authors' references and different theoretical perspectives, it became clear that most of the articles take the approaches of classic studies on environmental justice and political ecology. This is evidenced by the frequency with which authors such as Acselrad, Agyeman, Bullard, Pellow, and Schlosberg are cited. Additionally, central references to the theme of green gentrification, such as Gould, Lewis, and Anguelovski, were also frequently invoked.

In a 2008 paper, Budd (2008) used the term "green gentrification" to change cultural sources concerning urban sustainability in the United States, and in 2009, studies on green gentrification gained ground with the work of Gould and Lewis. The case studies revolved around New York or other locations within the United States. From 2013, with studies by Anguelovski (2013) the theme solidified in Europe and other countries. The year 2016 was an important one given the publication of Green gentrification: Urban sustainability and the struggle for environmental justice by Gould and Lewis (2016), which quickly became the most cited work on green gentrification (it currently has more than 400 mentions). This paved the way for many other researchers to test the limits, applicability, and challenges of using the notion of green gentrification in different realities, particularly in the Global South (Torres et al., 2021).

But what is Green Gentrification?

The gentrification process is commonly defined "as a process of neighborhood change through which the demographic, real estate, and business characteristics of a place reveal a transition toward a more educated, wealthy, whiter population, able to afford new or renovated pricier properties while also fomenting new cultural and consumption practices" (Cole et al., 2019, p. 3). Green Gentrification, in turn, can be defined as a process "which is facilitated in large part by the creation or restoration of an environmental amenity. Rather than cases where already gentrified neighborhoods develop constituents for local environmental amenities (where gentrification leads to greening)" (Gould and Lewis, 2012, p. 12). Gould and Lewis (2016) presented three questions in their studies related to race, class, and housing, which were central elements of their approach to green gentrification processes: (1) does sustainability whiten an area? (2) does greening enrich an area? (3) does greening increase rent and housing prices? These questions seem fundamental to urban greening in historical realities of the colonial past and present, such as in the Global South.

Concerning these contexts and particularities, Anguelovski and Irazábal-Zurita (2019) showed the roots of low-income populations' double dispossession process in urban areas of Medellín in relation to rural-to-urban migration, violence, land grabbing, and agricultural modernization. This same approach could be applied to several other territories in the Global South, which is hugely heterogeneous.

Perceiving these specificities is a challenge for scholars from the Global South, as is decolonizing (Anguelovski et al., 2021) and understanding how international agendas travel and impose themselves from north to south. A recent case study from the socalled Nature-Based Solutions (Kotsila et al., 2020; Tozer et al., 2020) centers around deciphering the narratives that create and recreate the process of greening cities. Is it true that polluting companies and large corporations are now sustainable? Who will profit from investing the billions of dollars cited in the initiative launched at The World Economic Forum's BiodiverCities? How many more millionaires will be produced by the time the next Oxfam report is published?

As shown by the different authors whose texts are published in this volume, it is always necessary to question the intentions of these processes (Meerow and Newell, 2016): for whom, what, when, where, and why?

The presence of a mini-review and a systematic review in the special issue contributes to a more systematic reading of this area of study. In Greening and Just Cities, de Souza and Torres presented a brief overview of the field covered by the Research Topic. The authors undertook a systematic review of research published in international peer-reviewed journals that analyzes environmental justice issues within the deployment of urban green amenities. Since most studies focus on the Global North, the authors' goal was to outline the similarities and differences regarding the nexus of justice and the greening of cities in both contexts to identify knowledge gaps in Global South studies. For this mini-review, de Souza and Torres chose to work with two descriptors, "green infrastructure" (GI) and "naturebased solutions" (NBS). Both notions, which were considered by the authors to be "leading concepts for cities' greening agendas," are analyzed in combination with "justice" and "green gentrification." Results show a need to better delineate a research agenda that addresses such issues in a heterogeneous Global South context, while also gaining insight from the advances made by research on the Global North. As the Global South will show the most rapid urban growth with numerous informal settlements and vulnerable places (Bai et al., 2018), it is essential to consider how Global South cities will use and take advantage of GI and $\mathrm{NbS}$ projects to address social and environmental inequalities. The authors further argue that future research ought to make proposals toward creating a just and resilient future for the Global South within an interdisciplinary agenda that should tackle climate justice and sustainable urban planning.

Urban Greening for New Capital Cities, by de Vries, aims to shed light on the contemporary discussion on relocating the capital city of Indonesia to a new location in Kalimantan and creating a new green capital city-this could possibly become the first capital relocation due to climate change effects of this century. For the Systematic Review, the article applies a meta-analytical approach by connecting the basic tenets of the proposed $8 \mathrm{R}$ framework of responsible land management to 
assess the pros and cons of a selected set of global capital city relocations and green cities. The findings reveal that each of the selected cases falls short in one or more aspects of the $8 \mathrm{R}$ framework. In all cases, constructing green capitals requires mixed and integrated land use planning, a transparent regulatory framework toward land use control, extensive consultation with both local, national, and international stakeholders, as well as the participation of local residents. de Vries' research also aims to support having more choices in the design and implementation processes of relocating the Indonesian capital city. Determining how such intentions should become reality, and what they imply, are the key objectives of his article. The author concludes that new capital city designs and the implementation of construction and planning activities inevitably require a fundamental and explicit framework when choosing to be green and responsible. Acknowledging aspects of spatial justice and inclusion in the design and execution processes is crucial. Furthermore, the design of greening should not be at the expense of existent tropical forests or cultural landscapes or designed in isolation of spatial justice and affordable housing strategies.

The Research Topic has five Original Research Articles. The themes explored by the authors include water, urban river interventions toward a just sociotechnical transition, decoloniality, coastal climate disasters, green inequality concerning industrial area renovation, using Google Street View for research, and Green Amenities. In Infrastructure in the Ruhr, Zimmermann and Lee examined the extent to which green infrastructure planned at the regional level can contribute to environmental justice within a city-region. They analyzed the context of this region with regard to the rehabilitation of environmental damages that occurred after more than 100 years of coal mining and steel production, investment in green infrastructure, and the creation of regional landscape parks as one of the main pillars of the economic and physical transformation of the region. The study examines the extent to which green infrastructure planned at the regional level can contribute to environmental justice within a city-region, and indicates that there is a need for a multi-scaled governance approach when it comes to green infrastructure. In terms of institutional design for environmental justice, this calls for a stronger coupling of regional and local initiatives and emphasizes that green infrastructure should also be planned at the local level. They argue that environmental justice is a question of scale, also in terms of politicization. Within this approach, the authors emphasize that actors from different disciplines must work together with the aim of developing and maintaining green infrastructure across all scales within a multi-scaled governance approach for green infrastructure.

In Emancipatory Urban Greening in the Global South, Porto et al. discussed theoretical, methodological, and political issues related to urban greening in the Global South, as well as emancipatory alternatives to envision more inclusive, democratic, sustainable, and healthy cities. The article emphasizes the idea that the concept of urban greening has its own specificity in the context of the Global South. In the Brazilian context, this involves understanding the complex relationship between traditional peoples and communities, as well as families and peasant agriculture; the existence and different forms of mobilization or social struggles experienced by these groups represent a vast pluri-verse of hues and hybridizations. As a synthesis of different experiences presented in the article, they represent emblematic expressions of ongoing social struggles at different levels, scales, and regions of the planet that can contribute to articulating the emancipatory agendas of the Global South and the Global North.

In Using Google Street View to Examine Urban Context and Green Amenities in the Global South Haddad et al. evaluated the use of virtual, human-interpreted, field observations from Google Street View (GSV) to examine the presence of conditions that may be used to analyze green gentrification in the Global South. Using a sample of four parks in two Chilean cities, they analyzed how green amenity indicators and urban contexts (explored via virtual field observations) represent the potential for green gentrification. The outcomes indicate that virtual field observations can provide a promising method that may facilitate the identification and investigation of the effects of green gentrification in the Global South, thus broadening the scope and application of this type of research in heterogeneous urban landscape, especially in cases with unreliable or unavailable data. The study highlights the importance of understanding the local context to develop relevant indicators based on street-level characteristics and that local knowledge about neighborhoods needs to be incorporated into the interpretation of indicators; thus, engaging local experts to guide greening decision-making is essential.

In Resilience Gentrification, Gould and Lewis argued that responses to climate events often result in greater inequality through a process they call "resilience gentrification." They emphasized that from the three possible resolutions to the coastal resilience dialectic-managed retreat, denial, and structural mitigation-the last one has become the most popular response in the Anthropocene. The authors illustrate the post-disaster recovery of two different communities: Gowanus, Brooklyn, New York, and the Caribbean island of Barbuda. They argue that these examples show that government responses did not consider and address the equity impacts of climate change resilience policies, and that current processes lead to resilience gentrification, whereby less wealthy coastal residents find themselves unable to remain in place, and public policy fails to adopt equity-based climate adaptation strategies. They recommend managed retreat and de-growth strategies for climate resilience through public policies that separate resilience from wealth and offer greater potential for a more just kind of sustainability.

In Urban River Interventions in São Paulo Municipality, Travassos and Momm discussed the sociotechnical transitions regarding urban rivers policy in São Paulo Municipality by focusing on programs and projects conducted since 2000. For the authors, policies and projects concerning the relationship between rivers and urban spaces-specifically through linear parks and other open spaces for leisure-have not been able to be configured as a new socio-technical regime. They emphasized the need to consider the context of two different cities with two different socio technical landscapes regimes. Inequality remains a relevant factor in peripheral and precarious areas and there is 
a need for a sociotechnical transition and the implementation of a new paradigm in the relationship between infrastructure and existing urban rivers. It is necessary to strengthen the link between the sociotechnical transition literature and that of justice, since an important part of the advances and setbacks are strongly related to the territorial inequalities of large cities in peripheral countries, which makes the analysis of the transition more complex.

Finally, the Research Topic presents some policy-oriented contributions for the discussion-one policy brief and three policy and practice reviews authored by academics and practitioners. The Policy Brief Green Gentrification and Environmental Injustice from Alves et al. is a contemporary and essential contribution as it directly engages with the themes of the Research Topic: both the issue of green gentrification itself and the use of greening narratives-or green makeup-in government programs, plans, and policies, such as the case of the Pinheiros River Depollution Program. Through the analysis of the River Program, environmental inequalities are exposed, thereby showing that vulnerable neighborhoods will receive only basic infrastructure, whereas Marginal Pinheiros, a rich area, will be equipped with additional leisure, sports, and cultural facilities. The policy brief focuses on current practices of producing and reproducing urban environmental inequalities, while also exposing and unmasking ongoing issues in the program.

Opening the final three articles on policy and practice review, Construction of Sustainable Territories and the Multiple Dimensions of Sustainability, Marques and Alvim explored the relationship between legal frameworks, urbanization, and the environment in the context of metropolitan fringes focusing on the Juqueri-Cantareira sub-basin: a strategic territory for the ecosystemic balance of the São Paulo Metropolitan Region (SPMP), Brazil. The study sought to determine how these instruments articulate and incorporate these dimensions to promote strategies that contribute to sustainable development and address socio-spatial inequalities in the region. The results revealed that although the instruments analyzed did address the dimensions of sustainability defined for the study, a sectoral fragmented view prevailed, as did the model of a sprawling city. As a policy contribution, the article concludes that the planning process should be reviewed to provide an integrated vision of regional scope that values the territory, environmental heritage, and local communities.

Caetano et al. discussed São Paulo's Environmental Quota (EQ), which is a wide range of principles developed between 2013 and 2016 associated with environmental services and the consideration that green areas in this megacity are unequally distributed. This is the main contribution of authors at The City of São Paulo's Environmental Quota. This paper details

\section{REFERENCES}

Anguelovski, C., and Irazábal-Zurita, J. J. T. (2019). Connolly grabbed urban landscapes: socio-spatial tensions in green infrastructure planning in Medellín. Int. J. Urban Reg. Res. 43, 133-156. doi: 10.1111/1468-2427. 12725 the political-institutional context in which the EQ and its guidelines were established and implemented, and provides a general overview of the tools and theoretical frameworks within which it was developed; finally, it discusses the complex social decision-making process of its legal constraints. Moreover, it analyzes the implementation and application of the EQ to examine its effectiveness and how it relates to the city's gentrification. The replicability potential of the EQ to expand both the supply and distribution of green infrastructure and environmental services throughout the urban environment is considered, thereby contributing to the mitigation of intricate problems within urban environments in the Global South.

Another article on São Paulo, or its Metropolitan Region, Socio-Ecological Conflicts in a Global South Metropolis by Moreno et al. explored the greenways concept as a measure of environmental remediation within a broad framework aimed at promoting urban greening and adaptation to climate change. This policy and practice review examines the socioeconomic and environmental processes that shaped this potential urban greenway between Santo André, Mauá, and Ribeirão Pires, which are part of the São Paulo Metropolitan Region. The authors state that the implementation of green infrastructure should be based on local needs. Their findings indicate that the performance of green infrastructure in informal settlements may support the evolution of "slum upgrading" through local parameters, which will promote ecological and economic benefits for the region and expand the total green coverage of the municipalities. At the same time, the authors scientifically aim to contribute to research on urban greenways, green infrastructure, and ecosystem-based adaptation in cities within the Global South, therefore seeking to demonstrate the value of implementing green infrastructure solutions to planners and decision-makers.

Undoubtedly, there is still much research to be conducted in this area, as the relevance of urban greening, green gentrification, and critical paths toward just sustainabilities continues to grow. We hope this special issue inspires more research on these issues from the perspective of the Global South or with a view to create a South-North dialogue.

\section{AUTHOR CONTRIBUTIONS}

PT: conceptualization. PT, PJ, and CI: writing-original draft preparation. All authors contributed to the article and approved the submitted version.

\section{FUNDING}

The São Paulo Research Foundation (FAPESP) funded this research, Grant Number 2018/06685-9. 
Bai, X., Dawson, R. J., Ürge-Vorsatz, D., Delgado, G. C., Salisu Barau, A., Dhakal, S., et al. (2018). Six research priorities for cities and climate change. Nature. 555, 23-25. doi: 10.1038/d41586-018-02409-Z

Budd, W. (2008). Cultural sources of variations in US urban sustainability attributes. Cities. 25, 257-267.

Cole, H. V. S., Triguero-Mas, M., Connolly, J. J. T., and Anguelovskia, I. (2019). Determining the health benefits of green space: does gentrification matter? Health Place. 57, 1-11. doi: 10.1016/j. healthplace.2019.02.001

Gould, K., and Lewis, T. (2012). "The environmental injustice of green gentrification: The case of Brooklyn's Prospect Park," in The World in Brooklyn: Gentrification, Immigration, and Ethnic Politics in a Global City, eds J. DeSena and T. Shortell (Lanham, MD: Lexington Books), 113-146.

Gould, K., and Lewis, T. (2016). Green Gentrification: Urban Sustainability and the Struggle for Environmental Justice. Abingdon; New York, NY: Routledge.

Kotsila, P., Anguelovski, I., Baró, F., Langemeyer, J., Sekulova, F., and Connolly, J. J. T. (2020). Nature-based solutions as discursive tools and contested practices in urban nature's neoliberalization processes. Environ. Plan. E Nat. Space. 4, 254-274. doi: 10.1177/25148486209 01437

Meerow, S., and Newell, J. P. (2016). Urban resilience for whom, what, when, where and why? Urban Geogr. 40, 309-329. doi: 10.1080/02723638.2016. 1206395

OXFAM (2022). Inequality Kills: The Unparalleled Action Needed to Combat Unprecedented Inequality in the Wake of COVID-19. Available online at: https://www.oxfam.org/en/press-releases/ten-richest-men-double-theirfortunes-pandemic-while-incomes-99-percent-humanity (accessed January 17, 2022).
Torres, H. C., de Souza, T. P., Empinotti, L., and Jacobi, R. (2021). Green Gentrification and contemporary capitalist production of space: notes from Brazil. Cahiers Amériques Latines. 97, 179-205.

Tozer, L., Hörschelmann, K., Anguelovski, I., Bulkeley, H., and Lazova, Y. (2020). Whose city? Whose nature? Towards inclusive nature-based solution governance. Cities. 107, 102892. doi: 10.1016/j.cities.2020.102892

World Economic Forum (2022). BiodiverCities by 2030: Transforming Cities' Relationship With Nature. Available online at https://www3.weforum. org/docs/WEF_BiodiverCities_by_2030_2022.pdf (accessed January 17, 2022).

Conflict of Interest: The authors declare that the research was conducted in the absence of any commercial or financial relationships that could be construed as a potential conflict of interest.

Publisher's Note: All claims expressed in this article are solely those of the authors and do not necessarily represent those of their affiliated organizations, or those of the publisher, the editors and the reviewers. Any product that may be evaluated in this article, or claim that may be made by its manufacturer, is not guaranteed or endorsed by the publisher.

Copyright (c) 2022 Torres, Irazábal and Jacobi. This is an open-access article distributed under the terms of the Creative Commons Attribution License (CC BY). The use, distribution or reproduction in other forums is permitted, provided the original author(s) and the copyright owner(s) are credited and that the original publication in this journal is cited, in accordance with accepted academic practice. No use, distribution or reproduction is permitted which does not comply with these terms. 